\title{
Parapharyngeal giant ganglioneuroma with multifocal bone involvement in a pediatric female patient
}

\author{
Asif Salimov ${ }^{1}$, Nilda Süslü${ }^{1}$, Oğuz Kuşçu ${ }^{1}$, Ahmet Emre Süslü${ }^{1}$, Mehmet Umut Akyol ${ }^{1}$, \\ Özay Gököz², Ece Özoğul² \\ ${ }^{1}$ Department of Otolaryngology Head and Neck Surgery, ${ }^{2}$ Department of Pathology, Hacettepe University Faculty of \\ Medicine, Ankara, Turkey. \\ E-mail: asifselimov2003@hotmail.com \\ Received: 21st March 2016, Revised: 10th May 2016, Accepted: 27th May 2016
}

SUMMARY: Salimov A, Süslü N, Kuşçu O, Süslü AE, Akyol MU, Gököz Ö, Özoğul E. Parapharyngeal giant ganglioneuroma with multifocal bone involvement in a pediatric female patient. Turk J Pediatr 2016; 58: 669-674.

Ganglioneuroma is a rare benign tumor that originates from neural crest. Tumor tends to be slow growing, asymptomatic but can cause symptoms because of pressure to neighboring structures. In the head and neck region they are relatively rarely seen. We hereby present a rare case of multiple ganglioneuromas that were located in parapharyngeal space, iliac bone and other bones in a 13-year-old girl. Patient underwent surgery for the excision of a large mass, extending from parapharyngeal space to neck, with transparotid and transcervical combined approach. After operation, MIBG (iodine-123meta-iodobenzylguanidine) scintigraphy was performed and involvement of parietooccipital bone, lumbal vertebra, right iliac wing medial cortex and left humerus were detected. No adjuvant therapy was given to the patient. There is no evidence of recurrence in the head and neck region in the following 12 months. In conclusion, complete surgical excision of the tumor, if possible, is the treatment of choice with high success rate. Close clinical and radiological follow-up for these tumors after surgery should be made.

Key words: ganglioneuroma, parapharyngeal space, multifocal, bone, pediatric.

Ganglioneuroma is a benign neurogenic tumor that originates from sympathetic ganglions which differentiated embriologically from neural crest. The most commonly affected sites are the posterior mediastinum, the retroperitoneum and the adrenal gland ${ }^{1}$. In the head and neck region they are relatively rarely seen. Tumor tends to have a slow growth rate and is usually asymptomatic but can cause symptoms because of pressure to neighboring structures. In this paper, we describe a unique case of multiple ganglioneuromas that were located in parapharyngeal space, iliac bone and other bones in the same patient.

\section{Case Report}

A 13-year-old female patient was admitted to our clinic with a swelling on the left side of the neck that occurred for four years. There was no history of swallowing difficulty, respiratory distress, limitation of neck movement. Physical examination revealed a mass with soft consistency that fulfilled left level 2 and 3 of neck. Endoscopic examination of nasopharynx and larynx were normal. The cranial nerves were intact on examination. Magnetic resonance imaging (MRI) showed a large mass with $3.5 \times 4 \times 8 \mathrm{~cm}$ dimensions expanding between skull base and superior margin of thyroid gland (Figs. 1, and 2). Complete blood count and urine levels of vanylmandelic acid (VMA), homovalinic acid (HVA), dopamin, epinephrin and norepinephrin were normal. It was learned that fine-needle aspiration biopsy (FNAB) had been performed two times in a different clinical center, with suspicion of lymphoproliferative disease, with a non-diagnostic pathological report. In the admittance to our clinic, we performed tru-cut needle biopsy and diagnosis of ganglioneuroma was made.

Patient underwent an operation started with modified Blair incision extented to neck (Fig. 


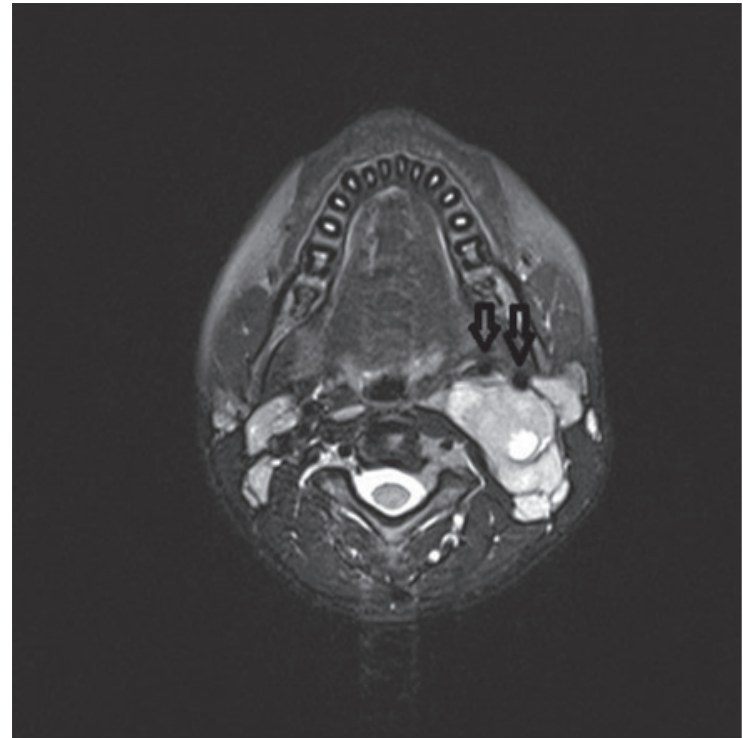

Fig. 1. T2 weighted axial MRI showed parapharyngeal mass pushing internal and external carotid artery (marked with downward arrows) to the lateral.

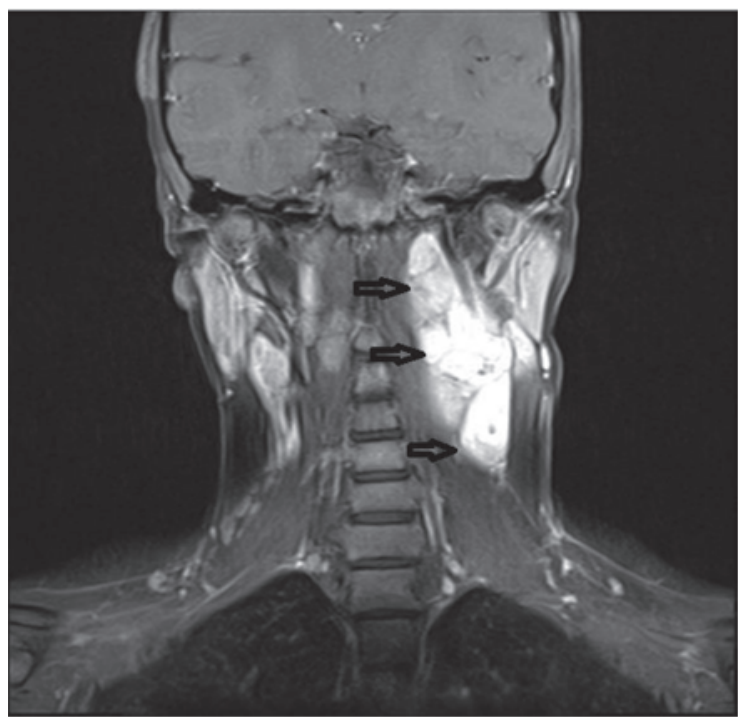

Fig. 2. T1 weighted postcontrast MRI showed parapharyngeal mass with skull base and neck extensions.

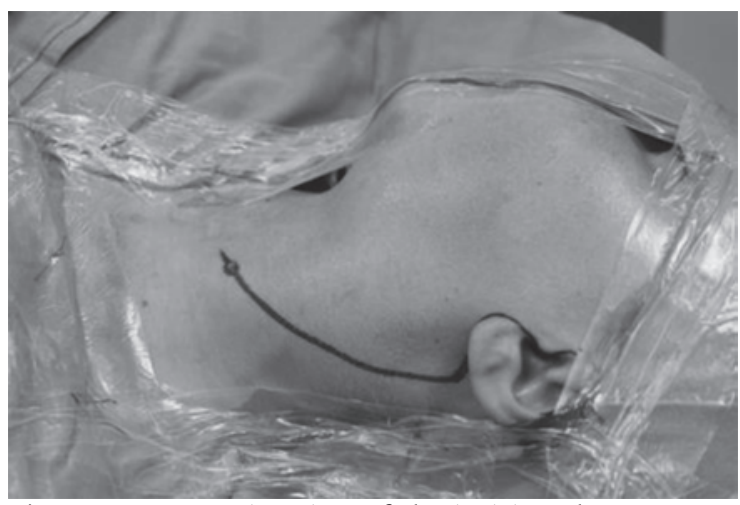

Fig. 3. Intraoperative view of the incision shape.
3). After identifying the facial nerve with the help of pointer cartilage landmark, partial parotidectomy was performed and posterior belly of digastric muscle was dissected and cut to increase exposure of parapharyngeal space. In the neck, subplatysmal flap was raised and then external jugular vein was ligated. The mass was attached to sternocleidomastoid (SCM) muscle medially, extended superiorly to the skull base near the medial side of jugular foramen and inferiorly to the superior margin of thyroid gland. SCM muscle was dissected from the superficial layer of deep cervical fascia and retracted laterally to see medial deep extension of the mass near the main blood vessels. Lateral deplacement of internal jugular vein was seen due to the mass effect. There were some adhesions between vagus nerve and mass. The tumor was dissected from parapharyngeal space with extension to skull base with blunt and sharp dissections. The adherent portion of the mass that adhered to vagus nerve and internal carotid artery followed to the superior side of thyroid gland and dissected bluntly and excised totally (Figs. 4 and 5).

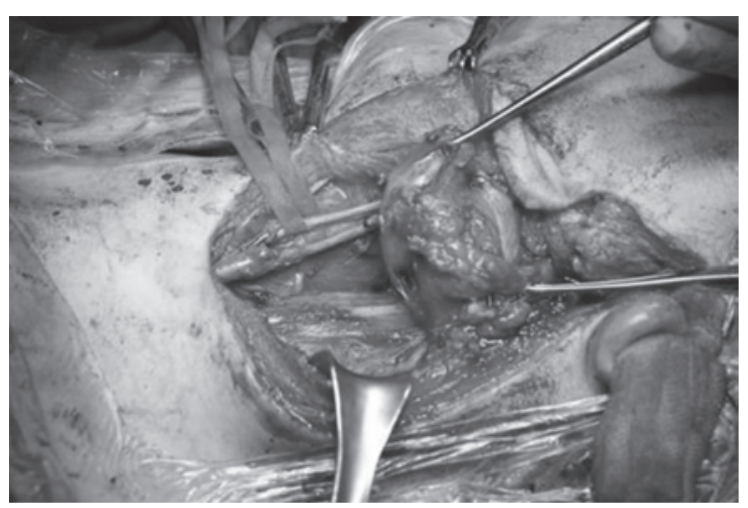

Fig. 4. Intraoperative view of the mass retracted to superior. Nylon tape held carotid artery and next to it internal jugular vein was seen.

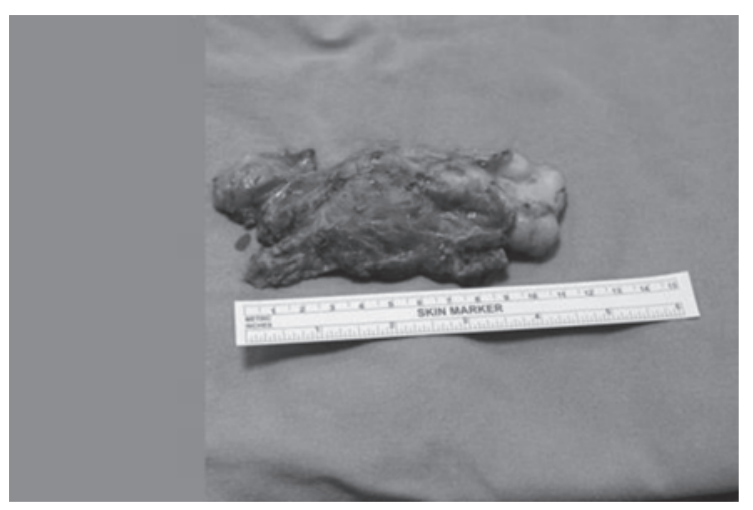

Fig. 5. The view of the mass after excision. 


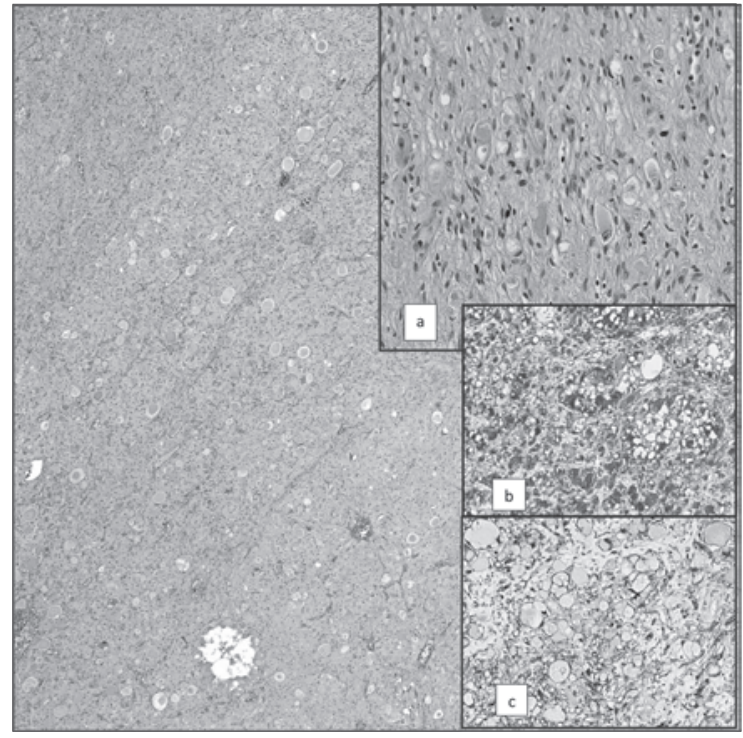

Fig. 6. Partially nodular solid neoplasm (hematoxylin and eosin stain, $\mathrm{x} 40$ ) (inset a: ganglionic cells in the Schwannian stroma, hematoxylin and eosin stain, x200; b: synaptophysin positive ganglion cells; and c: S100 positive stroma, immunoperoxidase stain, x100).

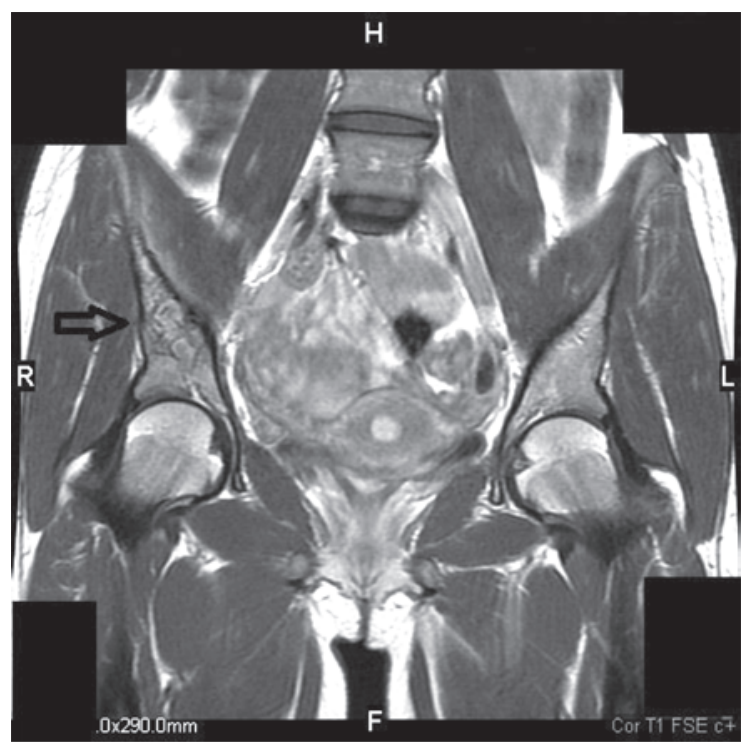

Fig. 7. T1 weighted coronal postcontrast fast spin echo (FSE) MRI showed right iliac bony irregularity (marked with arrow) compared to left iliac bone.

The excision specimen was somewhat nodular mass $11.5 \times 5.5 \times 4 \mathrm{~cm}$ in diameter, most parts were surrounded by a thin fibrous capsule. Cut sections revealed lobulated mass with cystic hemorrhagic areas. Specimen was thoroughly sampled and every sample beared a neoplasm made up of synaptophysin positive ganglionic cells embedded in a S100 positive Schwannian

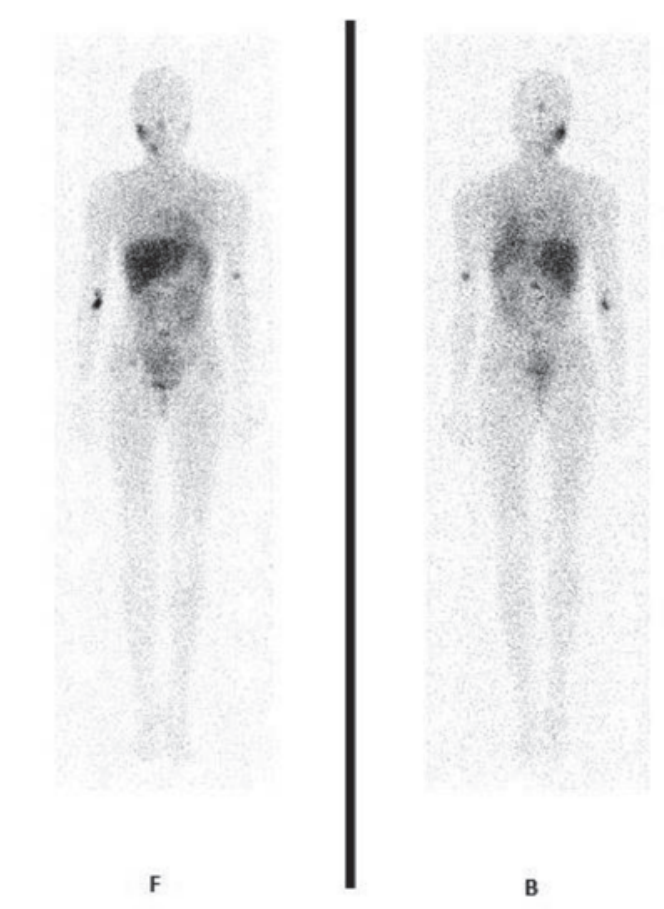

Fig. 8. MIBG scintigraphy showed multifocal bone involvement including parietooccipital bone, lumbal vertebra, right iliac wing medial cortex and left humerus (F: front; B: back) (Enhancement in the right cubital fossa was due to injection side).

stroma (Fig. 6). Most of the ganglionic cells were mature and there was no neuroblastic component. Ki-67 proliferation index was low. The final diagnosis was ganglioneuroma.

Postoperatively the patient had myosis and ptosis on the left side with anhidrosis revealing Horner syndrome. Cranial nerve examination showed left vocal cord paralysis. Other cranial nerves were intact. In the follow-up period, two months later, patient developed a swelling on the right hip and after excision pathology confirmed as intraosseous and extraosseous ganglioneuroma of iliac bone (Fig. 7). An MIBG (iodine-123-meta-iodobenzylguanidine) scintigraphy was performed to detect if the tumor had spread to any other sides of body. Involvement of parietooccipital bone, lumbal vertebra, right iliac wing medial cortex and left humerus were detected (Fig. 8). The patient was discussed in a multidisciplinary meeting with a decision of follow-up with close observation. Patient followed with periodic controls and close observation. There was no evidence of recurrence in the head and neck region in the following 12 months with MRI 


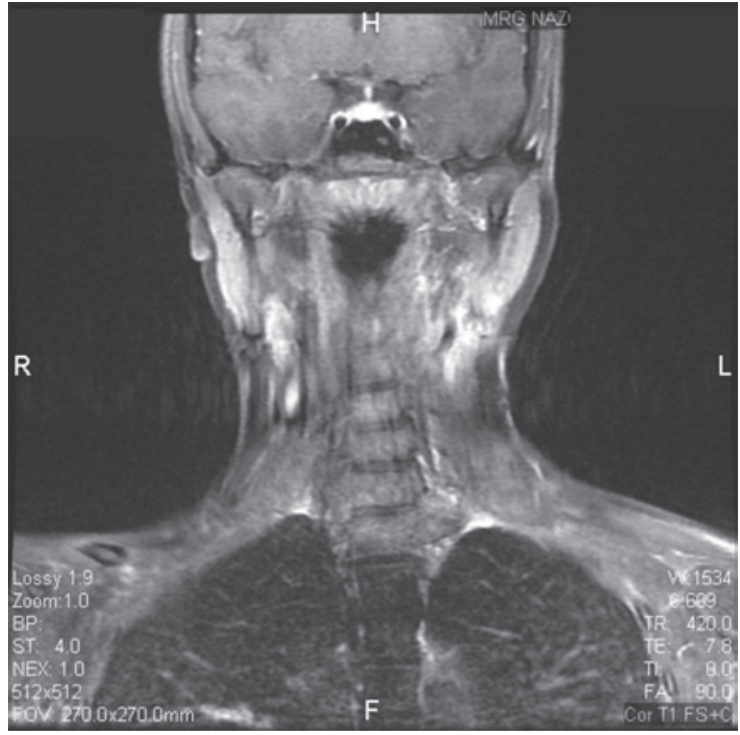

Fig. 9. T1 weighted coronal fat saturated (FS) MRI (postoperatively) showed complete resection of tumor.

confirmation (Fig. 9).

\section{Discussion}

Ganglioneuromas were first described by Loretz in 1870 and first reported as occurring in the neck by de Quervain in 1899. Sixty percent of patients with ganglioneuromas are under 20 years of age; the average age of presentation is approximately 11 years with a slight preponderance of female cases ${ }^{2}$. From a pathohistological point of view, ganglioneuromas, ganglioneuroblastomas and neuroblastomas are closely related tumors. Neuroblastomas are highly malignant tumors composed of undifferentiated neuroblasts. Ganglioneuroblastomas are malignant tumors composed of a mixture of neuroblasts and ganglion cells in various stages of differentiation. Benign ganglioneuromas consist of mature ganglion and Schwann cells and represent the other end of the spectrum. Several hypotheses have been proposed to explain the origin of ganglioneuromas, including spontaneous maturation of neuroblasts of a neuroblastoma to differentiated ganglion cells, the differentiation of remnant cells of the embryonic neural crest or the necrosis of neuroblasts during the early tumor stages with sparing of the mature ganglion cells and the neuromatous stroma ${ }^{3}$.

In the head and neck region ganglioneuromas are relatively rarely seen. Ma et al. ${ }^{4}$ reviewed 26 cases of cervical ganglioneuroma and reported that the cervical sympathetic chain is the most frequent structure of origin in the neck. Other sides of origin include the larynx, pharynx and ganglion nodosum of the vagus nerve. There is also a reported case of parapharyngeal ganglioneuroma of hypoglossal nerve origin ${ }^{5}$.

Ganglioneuroma may present with metabolic activity such as increased secretion of catecholamines. The elevated catecholamines increase the levels of vanylmandelic acid (VMA) or homovalinic acid (HMA) in the plasma or urine causing hypertension, diarrhea, sweating, flushing, renal acidosis and other symptoms of catecholamine excess ${ }^{6,7}$. But in our case there was no evidence of metabolic activity both clinically and biochemically.

A precise preoperative histological diagnosis of ganglioneuroma is difficult. A variety of methods are available. Fine-needle aspiration cytology as a diagnostic procedure is not always conclusive for ganglioneuroma. When performed preoperatively, it failed to identify the tumor in $60 \%$ of cases. A catecholaminergic crisis has never been described subsequent to fine-needle aspiration of a neck mass, but this theoretical possibility exists. The value of a preoperative incisional biopsy is uncertain because although it may provide a conclusive diagnosis, the tissue planes will be obliterated, and unforeseen metabolic complications may occur ${ }^{8,9}$. In our patient FNAB was performed two times at another institution but none of them was diagnostic. In our clinic, pathological diagnosis was made by tru-cut biopsy.

Histopathological examination of a tru-cut biopsy can be troublesome since it can only represent a part of the mass masquerading the different morphologic components of a neurogenic tumor. Immunohistochemical analysis of this tissue can give better assumptions for the diagnosis and these were done for the tru-cut biopsy, too. Clinical features and laboratory work-up were also opposing the diagnosis of neuroblastoma or a tumor with a distinct neuroblastic component.

Due to it's location, - neck and parapharyngeal space - like in our case, pleomorphic adenoma, schwannoma, lymphangioma, carotid body tumor, branchial cleft cyst, lipoma, lymphoma should be considered in the differential diagnosis. There is also a case report in the literature ganglioneuroma of the neck whose 
location suggested a thyroid nodule ${ }^{8}$. In our case also the mass was extending to thyroid gland level.

Radiological examinations are helpful to define borders of the mass but not enough for diagnosis. Ultrasonography reveals a homogeneous, hypoechoic mass with welldefined borders ${ }^{10}$. Computed tomography (CT) can show calcifications in the mass. Tissue discrimination and multiplanar imaging makes MRI superior to CT. Low intensity on T1weighted images (T1WI), marked high intensity on T2-weighted images (T2WI) and gradual increasing enhancement on dynamic MR images are typical appearances of ganglioneuromas. If a ganglioneuroma has atypical CT and MR features, coexistence of a malignant component should be considered ${ }^{11}$. Scintigraphically, MIBG uptake has been reported in up to $57 \%$ of ganglioneuromas in one study ${ }^{6}$. With these image characteristics it remains difficult to discriminate ganglioneuroma from other lesions in the cervical region, including salivary gland tumors (pleomorphic adenoma), other neurogenic tumors (neurolemmoma, neurofibroma and fibrosarcomas) and soft tissue lesions (fibrosarcomas, rhabdomyosarcomas and malignant lymphomas) ${ }^{4}$.

Ganglioneuromas are benign, mature tumors. However, malignant transformation to malignant schwannoma, malignant peripheral nerve sheath tumor, neuroblastoma and even rabdomyosarcoma sporadically has been reported in the literature ${ }^{5,12-20}$. Also there are reported cases of ganglioneuromas with neurofibromatosis 21,22 . Careful examination should be made considering possibility of neurofibromatosis and other neurogenic tumors. Multiple ganglioneuroma in cervical region was also been reported in the literature ${ }^{4}$. Intraosseous ganglioneuroma is exceedingly rarely seen. There are several cases described of intraosseous ganglioneuroma from spontaneous cytomaturation of metastatic neuroblastoma, ganglioneuroblastoma ${ }^{23-26}$. But in our case there is no history of neuroblastoma or ganglioneuroblastoma. Therefore, to our knowledge, this is the first case report in the English literature that ganglioneuroma in the neck with multifocal bone involvement.

Complete removal should be the aim of treatment only if it can be achieved without major risk for the patient and/or for neighboring structures. If necessary, incomplete resection is warranted and safe in view of the good prognosis of these tumors ${ }^{27}$. Further therapy, chemotherapy or radiotherapy, is not usually required, even for cases with partial excision. Symptoms of Horner's syndrome are often detected following surgery, but these symptoms are usually completely resolved within several months 4 .

As mentioned above ganglioneuromas are benign and we know that benign tumors do not have metastatic potential. But there are rare reports of metastatic ganglioneuromas. It is believed that these tumors represent metastases of neuroblastoma or ganglioneuroblastoma that have subsequently matured to ganglioneuroma; these patients have an excellent prognosis $6,28,29$. Ganglioneuromas are also documented to have arisen in the neuroblastomas after chemotherapy 28,30 . There are also reported rare cases of metastasis of ganglioneuroma without history of neuroblastoma or ganglioneuroblastoma ${ }^{31,32}$. In our case, there is also not any history of neuroblastoma or ganglioneuroblastoma. But we do not know if intraooseous ganglioneuroma is a metastatis of primary parapharyngeal tumor or the metastasis of a neuroblastoma or ganglioneuroblastoma that has matured to ganglioneuroma in the infancy period.

In conclusion, based on these findings, we suggest surgical excision of these tumors when possible and close clinical and radiological followup after surgery. Malignant transformation or metastasis possibility, like in our case, should be considered.

\section{REFERENCES}

1. Cavanaugh DA, Jawahar A, Harper J, McLaren BK, Wooten T, Kerr EJ. Cervical ganglioneuroma in an adult man: case report and literature review of a rare occurrence. J La State Med Soc 2010; 162: 218-221.

2. Kaufman MR, Rhee JS, Fliegelman LJ, et al. Ganglioneuroma of the parapharyngeal space in a pediatric patient. Otolaryngol Head Neck Surg 2001; 124: 702-704.

3. Müller A, Förster G, Behrendt W, Kosmehl H. Headache as an unusual presenting symptom of retropharyngeal ganglioneuroma. Acta Otolaryngol 2002; 122: 565-568.

4. Ma J, Liang L, Liu H. Multiple cervical ganglioneuroma: A case report and review of the literature. Oncol Lett 2012; 4: 509-512. 
5. Hallur N, Sikkerimath BC, Gudi SS, Chour G, Ginimav $S$, Nidoni MJ. Parapharyngeal ganglioneuroma of hypoglossal nerve in a 4-year-old girl: A rare case report. Maxillofac Oral Surg 2012; 11: 343-346.

6. Geoerger B, Hero B, Harms D, et al. Metabolic activity and clinical features of primary ganglioneuromas. Cancer 2001; 91: 1905-1913.

7. Lucas K, Gula MJ, Knisely AS, Virgi MA, Wollman M, Blatt J. Catecholamine metabolites in ganglioneuroma. Med Pediatr Oncol 1994; 22: 240-243.

8. Pucci A, Pucci E, Santini F, et al. A ganglioneuroma with features of a thyroid nodule: Intense pain on fine needle biopsy as a diagnostic clue. Thyroid 2009; 19 : 201-204.

9. Albuquerque BS, Farias TP, Dias FL, Torman D. Surgical management of parapharyngeal ganglioneuroma: Case report and review of the literature. ORL J Otorhinolaryngol Relat Spec 2013; 75: 240-244.

10. Lonergan GJ, Schwab CM, Suarez ES, Carlson CL. Neuroblastoma, ganglioneuroblastoma, and ganglioneuroma: Radiologic-pathologic correlation. Radiographics 2002; 22: 911-934.

11. Ichikawa T, Ohtomo K, Araki T et al. Ganglioneuroma: Computed tomography and magnetic resonance features. Br J Radiol 1996; 69: 114-121.

12. Ricci A, Jr, Parham DM, Woodruff JM, Callihan T, Green A, Erlandson RA. Malignant peripheral nerve sheath tumors arising from ganglioneuromas. Am J Surg Pathol 1984; 8: 19-29.

13. Moschovi M, Arvanitis D, Hadjigeorgi C, Mikraki V, Tzortzatou-Stathopoulou F. Late malignant transformation of dormant ganglioneuroma? Med Pediatr Oncol 1997; 28: 377-381.

14. Kulkarni AV, Bilbao JM, Cusimano MD, Muller PJ. Malignant transformation of ganglioneuroma into spinal neuroblastoma in an adult. Case report. J Neurosurg 1998; 88: 324-327.

15. Chandrasoma P, Shibata D, Radin R, Brown LP, Koss M. Malignant peripheral nerve sheath tumor arising in an adrenal ganglioneuroma in an adult male homosexual. Cancer 1986; 57: 2022-2025.

16. Fletcher CD, Fernando IN, Braimbridge MV, McKee $\mathrm{PH}$, Lyall JR. Malignant nerve sheath tumour arising in a ganglioneuroma. Histopathology 1988; 12: 445448 .

17. Damiani S, Manetto V, Carrillo G, Di Blasi A, Nappi $\mathrm{O}$, Eusebi V. Malignant peripheral nerve sheath tumor arising in a "de novo" ganglioneuroma. A case report. Tumori 1991; 77: 90-93.

18. Drago G, Pasquier B, Pasquier D, et al. Malignant peripheral nerve sheath tumor arising in a "de novo" ganglioneuroma: A case report and review of the literature. Med Pediatr Oncol 1997; 28: 216-222.
19. Meng ZH, Yang YS, Cheng KL, Chen GQ, Wang LP, Li W. A huge malignant peripheral nerve sheath tumor with hepatic metastasis arising from retroperitoneal ganglioneuroma. Oncol Lett 2013; 5: 123-126.

20. Kimura S, Kawaguchi S, Wada T, Nagoya S, Yamashita T, Kikuchi K. Rhabdomyosarcoma arising from a dormant dumbbell ganglioneuroma of the lumbar spine: A case report. Spine 2002; 27: E513-E517.

21. Sinha P, Sharma SC, Agarwal S, et al. Parapharyngeal ganglioneuroma with neurofibromatosis: An unusual presentation. Ann Otol Rhinol Laryngol 2011; 120: 769-774.

22. Miyakoshi N, Hongo M, Kasukawa Y, Misawa A, Shimada Y. Bilateral and symmetric C1-C2 dumbbell ganglioneuromas associated with neurofibromatosis type 1 causing severe spinal cord compression. Spine J 2010; 10: 11-15.

23. Kang DG, Helgeson MD, Britt JD, Tracey RW, Bernstock JD. Multifocal intraosseous ganglioneuroma. Am J Orthop (Belle Mead NJ) 2014; 43: E232-236.

24. Mithöfer K, Grabowski EF, Rosenberg AE, Ryan DP, Mankin HJ. Symptomatic ganglioneuroma of bone. A case report. J Bone Joint Surg Am 1999; 81: 15891595.

25. Garvin JH Jr, Lack EE, Berenberg W, Frantz CN Ganglioneuroma presenting with differentiated skeletal metastases. Report of a case. Cancer 1984; 54: 357 360.

26. Wilber MC, Woodcock JA. Ganglioneuromata in bone; report of a case. J Bone Joint Surg Am 1957; 39 $1385-1388$.

27. Sánchez-Galán A, Barrena S, Vilanova-Sánchez A, et al. Ganglioneuroma: to operate or not to operate. Eur J Pediatr Surg 2014; 24: 25-30.

28. DasGupta S, Das RN, Mishra PK, Chatterjee U, Datta C. Metastatic ganglioneuroma: A misnomer. Indian J Pathol Microbiol 2014; 57: 445-446.

29. Hayes FA, Green AA, Rao BN. Clinical manifestations of ganglioneuroma. Cancer 1989; 63: 1211-1214.

30. Ambros IM, Zellner A, Roald B, Amann G, Ladenstein $\mathrm{R}$, Printz D. Role of ploidy, chromosome $1 \mathrm{p}$, and Schwann cells in the maturation of neuroblastoma. N Engl J Med 1996; 334: 1505-1511.

31. Srinivasan R, Koliyadan KS, Krishnand G, Bhat SS Retroperitoneal ganglioneuroma with lymphnode metastasis: a case report. Indian J Pathol Microbiol 2007; 50: 32-35.

32. Jung HR, Kang KJ, Kwon JH, Kang YN. Adrenal ganglioneuroma with hepatic metastasis. J Korean Surg Soc 2011; 80: 297-300. 